\title{
Health status of regularly physically active persons with spinal cord injury
}

\author{
Lene C. Vik $\mathbb{D}^{1,2} \cdot$ Anne M. Lannem² ${ }^{2}$ Britt Marie Rak ${ }^{2} \cdot$ Trine Stensrud $^{1}$
}

Received: 23 April 2017 / Revised: 16 October 2017 / Accepted: 17 October 2017

(c) The Author(s) 2017. This article is published with open access

\begin{abstract}
Study design A non-controlled cross-sectional study.

Objectives To make a descriptive examination of health status in persons with paraplegia and tetraplegia who exercise regularly according to Canadian guidelines.

Settings Sunnaas Rehabilitation Hospital and the Norwegian School of Sport Sciences.

Methods Eighteen persons (men/women =9/9), aged 41-72 years with spinal cord injury (SCI), who exercise regularly were included. Post-injury years ranged from 4 to 48 years. Clinical examination of body composition, bone mineral density (BMD), forced vital capacity (FVC), forced expiratory volume in one second $\left(\mathrm{FEV}_{1}\right)$, diffusion capacity $\left(\mathrm{DL}_{\mathrm{CO}}\right)$, cardiorespiratory fitness $\left(\mathrm{VO}_{2 \max }\right)$, and self-reported quality of life (QOL) obtained by questionnaire was performed. Lung function results are presented as $\%$ predicted and $\mathrm{VO}_{2 \max }$ as absolute values relative to body weight. All results are given as median and range.

Results Persons with paraplegia $(n=13)$ were defined as overweight with fat mass 42\% (25-51). BMD $1.047 \mathrm{~g} \mathrm{~cm}^{-2}$ $(0.885-1.312)$ was within normal range. FVC $95 \%$ predicted $(60-131), \mathrm{FEV}_{1} 90 \%$ predicted $(61-119), \mathrm{DL}_{\mathrm{CO}} 77 \%$ predicted (56-103), and $\mathrm{VO}_{2 \max } 16.66 \mathrm{ml} \mathrm{kg}^{-1} \mathrm{~min}^{-1}$ (12.15-25.28) defined good aerobic capacity according to age controlled reference values (18). Persons with tetraplegia $(n=5)$ were slightly overweight with fat mass $35 \%$ (26-47). BMD $1.122 \mathrm{~g}$ $\mathrm{cm}^{-2}(1.095-1.299)$ was within normal range. FVC $72 \%$ predicted (46-91), $\mathrm{FEV}_{1} 75 \%$ predicted (43-83), $\mathrm{DL}_{\mathrm{CO}} 67 \%$ predicted (56-84), and $\mathrm{VO}_{2 \max } 16.70 \mathrm{ml} \mathrm{kg}^{-1} \min ^{-1}$ (9.91-21.01) defined excellent aerobic capacity according to reference values (18). QOL was ranked as median 7.5 (0-10 scale).

Conclusions Persons with SCI who exercise regularly following the Canadian guidelines responded with rather positive associations for health outcomes. Additional research is needed to strengthen our findings.
\end{abstract}

\section{Introduction}

Persons with spinal cord injuries (SCI) are reported to be especially inclined to develop secondary health complications. It has been suggested that these complications are responsible for the increased mortality in persons with chronic SCI and are related to potentially treatable factors. Osteoporosis, type II diabetes, and heart disease are examples of conditions that are related to inactivity [1]. However, depending on the level and completeness of injury, SCI may cause varying extents of disability. For

\footnotetext{
Lene C. Vik

lene_cv@hotmail.com

1 Norwegian School of Sport Sciences, Oslo, Norway

2 Sunnaas Rehabilitation Hospital, Nesodden, Norway
}

some persons, this will limit their ability to perform physical activity in certain ways and can explain the most common cause of deconditioning in this population. It has also been suggested that loss of independence and physical fitness may lead to withdrawal from society and may negatively impact the quality of life (QOL) [2].

Positive associations between health and physical activity in the SCI population have been well established [3]. Even so, the level of physical activity varies. Jørgensen and coauthors investigated participation in leisure time physical activity (LTPA) among older adults with long-standing SCI [4]. Almost one-third reported no LTPA during a day. Of those who did, walking and wheeling were the most prevalent activities. Half of the participants performed less than five minutes LTPA at moderate to vigorous intensity [4]. To gain health benefits, activities at this intensity level are required [5]. To improve health in terms of fitness and 
QOL, promoting physical activity is considered to be of great importance. In addition, Canadian researchers have developed evidence-informed, consensus physical activity guidelines targeting persons with SCI [5]. These guidelines indicate type, amount, and intensity of physical activity. An evaluation showed improvements in certain aspects of aerobic and muscular fitness [6]. However, whether the guidelines are robust enough to provide health benefits is discussed [7-9].

It has been reported that there is a lack of health programs promoting participation in physical activity for persons with SCI [10]. In Oslo, Norway, Sunnaas Rehabilitation Hospital Outpatient Clinique for Exercise (SRHOCE) was established in early 2015. The purpose was to offer exercise classes twice a week according to Canadian guidelines to persons with chronic SCI or other disabilities [5]. As far as we know, no extensive screening of health status in persons with SCI who exercise regularly according to these guidelines has been reported. The overall aim of this study was to make a descriptive examination of health status in persons with paraplegia (PP) and tetraplegia (TP) who exercise regularly at SRHOCE. The following research questions were formulated:

1. What is the physical health status regarding body composition, bone mineral density (BMD), lung function, and cardiorespiratory fitness for persons with PP and TP who exercise regularly at least twice a week?

2. What is their self-perceived QOL?

\section{Methods}

\section{Study design}

A non-controlled cross-sectional study, involving clinical examinations and a self-reported questionnaire, was performed during the autumn of 2016. In order to detect differences in cardiorespiratory fitness from previous examinations, a retrospective inspection of medical records was done. The study was conducted in cooperation between Sunnaas Rehabilitation Hospital (SRH) and the Norwegian School of Sport Sciences (NSSS).

\section{Training program}

The training program at SRHOCE was developed in accordance with the Canadian guidelines, with aerobic activity and strength training two times a week. One class was chairobics, including strength exercises with manuals. The other class was circuit training, with aerobic exercises like boxing, interval wheeling, armergometer, and rope- slam. Strength exercises were performed with elastic bands, manuals, and pulley. Each class lasted $55 \mathrm{~min}$ in total, where at least 20 min consisted of aerobic activity. Strength training was performed with 8-10 repetitions in series of 3, with an intensity equivalent to $70-80 \%$ of 1 repetition maximum, as suggested [5]. Intensity level of the aerobic activity was pursued to be of a moderate to vigorous intensity, meaning an intensity between $60 \%$ and $80 \%$ of maximum heart rate (HR), as suggested [5]. The overall training program was carried out from January to June (summer holidays in July) and from August until middle of December each year.

\section{Subjects}

Participants were recruited from SRHOCE. In total 18 participants, nine males and nine females, aged 41-72 years with PP AIS [ASIA (American Spinal Injury Associations) Impairment Scale] A-B $(n=9)$, PP AIS C-D $(n=4)$, TP AIS A-B $(n=3)$, and TP AIS C $(n=2)$ signed up for this study. Inclusion criteria were persons with SCI who had followed the program for at least 6 months and had been exercising a minimum of two times a week for the last four weeks. All participants underwent a medical examination prior to training. No serious injuries were reported, and participants were declared fit to follow the training program.

\section{Data collection and measurements}

All data were collected between September and November 2016. Questionnaires were delivered to participants and then returned after a workout session. Injury-related data and previous results from maximal exercise tests were extracted from the medical records at SRH. Clinical examination was done in the laboratories at NSSS and at the Division of Clinical Nutrition at Oslo University.

\section{Body composition and bone measurement}

Total body BMD and body composition were measured by dual energy X-ray absorptiometry (DXA) (Lunar iDXA Prodigy, Madison, USA). Soft tissue body composition, including fat mass (FM kg), percentage fat mass (FM \%), lean tissue mass (LM kg), percentage lean mass (LM \%), and visceral adipose tissue (VAT) were derived from the total body scan. Scanning was performed by two different operators who followed the standard procedures. The BMD $Z$-score was obtained from the manufacturer's database by comparison with age- and gender-matched references. $Z$-score values $<-2.0$ were considered to be below the expected range for age according to The International Society for Clinical Densitometry (ISCD) [11]. 
Pulmonary function, ventilatory capacity, diffusion capacity, and airway inflammation

Pulmonary function, ventilatory capacity, and diffusion capacity were performed by using Masterscreen PTF (Jaeger Würzburg, Germany), according to European standards [12]. Pulmonary function measurements included maximal expiratory flow volume loops with forced vital capacity (FVC), forced expiratory volume in $1 \mathrm{~s}\left(\mathrm{FEV}_{1}\right)$, and maximal voluntary ventilation (MVV). Diffusion capacity of carbon monoxide $\left(\mathrm{DL}_{\mathrm{CO}}\right)$ was assessed with the singlebreath method according to the standard protocol [13]. Results are expressed as percentage of predicted values based on age, sex, weight, and height [14]. The fraction of exhaled nitric oxide $\left(\mathrm{FE}_{\mathrm{NO}}\right)$ was assessed with the singlebreath online test with a chemiluminescent analyzer EcoMedics CLD 88 Exhalyzer® (Eco Medics AG, Duerten, Switzerland). $\mathrm{FE}_{\mathrm{NO}}$ is a marker of eosinophilic airway inflammation and was determined according to the standard protocol [15].

\section{Cardiorespiratory fitness}

Maximal oxygen uptake $\left(\mathrm{VO}_{2 \max }\right)$ was measured with an incremental cardiopulmonary exercise test (CPET) on an arm ergometer (Ergometrics 800, Ergoline, Germany) until the participant reached exhaustion. The participant was connected to a gas analyzer (OxyconPro, Jaeger, Würtzburg, Germany) with a facemask covering the nose and the mouth. For safety reasons, blood pressure was assessed with an automatic blood pressure device (Welch Allyn Spot Vital Signs LXi, NY, USA). HR was determined with a heart rate monitor (Polar Electro Oy, Kempele, Finland). After warming up, exercise periods of 3 min were started with a minimum of 60 revolutions per minute (rpm). In a oneminute break between the exercise sessions, blood pressure, HR, and Borg Scale values were obtained. The start load and the increasing workload (from 5 to $30 \mathrm{~W}$ ) for each exercise session were determined individually according to age, level of injury, and expected fitness status. The sessions continued until the participant reached exhaustion or were discontinued if the participants wanted to stop at any time. The end criteria for approved measurements consisted of several parameters: the Borg Scale $\geq 17, \mathrm{VO}_{2 \max }$ reached a plateau even if the intensity increased, or the respiratory exchange ratio (RER) was $>1.1 . \mathrm{VO}_{2 \max }$ was expressed as $\mathrm{ml} \mathrm{min}{ }^{-1}$ and $\mathrm{ml} \mathrm{kg}^{-1} \mathrm{~min}^{-1}$, and minute ventilation (VE), $\mathrm{HR}$, and RER were noted and used for further analysis. Breathing reserve (BR) was calculated (MVV-VE) and expressed as a percentage. The evaluation of the maximal $\mathrm{HR}$ was based on expected age-predicted $\mathrm{HR}_{\max }$ from the HUNT fitness study [16]. The level of injury was corrected for when evaluated.
Quality of life

A Norwegian version of a questionnaire from The International SCI QOL Basic Data Set was used to assess QOL. This element was included in a questionnaire that was distributed to participants and then returned after the workout. The International SCI QOL contains three items that are each self-rated on a $0-10$ scale, with $0=$ completely dissatisfied and $10=$ completely satisfied [17]. The first item concerned satisfaction with personal circumstances, the second was satisfaction with physical health, and the third item concerned satisfaction with mental health. The time frame of self-rated satisfaction was four weeks.

\section{Statistical analysis}

Statistical analysis was conducted with SPSS (Version 21, IBM SPSS Statistics Data Editor). Descriptive statistics are used to present basic characteristics and measurement outcomes. Due to the small sample size $(n=18)$, all data are presented in median and range (minimum, maximum) unless otherwise stated. To detect differences in injury level and sexes, variables were assessed with the Mann-Whitney $U$ test for independent samples. For comparison of $\mathrm{VO}_{2 \max }$ measured in the present study and previously measured $\mathrm{VO}_{2 \max }$, One-Sample Wilcoxon Signed-Rank Test was used. Correlation between variables was evaluated using Spearman's correlation analysis. Statistical significance was set at $p \leq 0.05$. All tables and figures were compiled in Excel for Mac 2015 (version 15.29.1).

\section{Results}

Descriptive characteristics are presented in Table 1. Except for height, none of the variables showed significant differences between males and females.

\section{Physiological results}

Physiological differences between levels of injury were only significant for $\mathrm{FVC}$ and $\mathrm{FEV}_{1}(\%$ predicted, $p<0.05$ ) in persons with PP (AIS A-B) and PP (AIS C-D). FEV $_{1}(\%$ predicted) was the only significant different variable when comparing PP and TP $(p<0.05)$. Physiological variables for gender revealed significant differences only in $\mathrm{FEV}_{1}(\%$ predicted) and total LM $(p>0.05)$. Due to minor differences, gender was merged in the other analyses. Physiological results for PP (AIS A-B) and PP (AIS C-D), TP (AIS $\mathrm{A}-\mathrm{B})$ and $\mathrm{TP}(\mathrm{C})$ are presented in Table 2. Individual results for body composition and BMD, pulmonary function, ventilatory capacity, and $\mathrm{DL}_{\mathrm{CO}}$ are presented in Table 
Table 1 Basic characteristics

\begin{tabular}{|c|c|c|c|}
\hline Variable & $\begin{array}{l}\text { Paraplegia } \\
(n=13)\end{array}$ & $\begin{array}{l}\text { Tetraplegia } \\
(n=5)\end{array}$ & $p$ value \\
\hline \multicolumn{4}{|l|}{ Male } \\
\hline \multicolumn{4}{|l|}{ Female } \\
\hline Age (years) & $58(50-72)$ & $47(41-64)$ & 0.15 \\
\hline Height $(\mathrm{cm})$ & $\begin{array}{l}167(153 \\
-190)\end{array}$ & $\begin{array}{l}178 \\
(162-181)\end{array}$ & 0.18 \\
\hline Weight $(\mathrm{kg})$ & $66(46-113)$ & $75(37-85)$ & 0.46 \\
\hline BMI $\left(\mathrm{kg} \mathrm{m}^{-2}\right)$ & $24(18-39)$ & $24(14-48)$ & 0.88 \\
\hline Time (years) since injury & $18(4-54)$ & $30(19-47)$ & 0.24 \\
\hline AIS A-B & $9(69 \%)$ & $3(60 \%)$ & \\
\hline AIS C-D & $4(31 \%)$ & $2(40 \%)$ & \\
\hline \multicolumn{4}{|l|}{ Exercise } \\
\hline 1 time a week & 0 & $1(20 \%)$ & \\
\hline 2 times a week & $7(54 \%)$ & $1(20 \%)$ & \\
\hline$>3$ times a week & $6(46 \%)$ & $3(60 \%)$ & \\
\hline $\begin{array}{l}\text { More physically active now } \\
\text { than before }\end{array}$ & $8(73 \%)$ & $7(100 \%)$ & \\
\hline Smoking & $2(15 \%)$ & 0 & \\
\hline \multicolumn{4}{|l|}{ Education level } \\
\hline$<7$ years primary school & $1(8 \%)$ & 0 & \\
\hline $7-10$ years primary school & 0 & $1(6 \%)$ & \\
\hline $1-2$ years high school & $2(15 \%)$ & 0 & \\
\hline 3 years high school & $4(31 \%)$ & $1(20 \%)$ & \\
\hline College/university bachelor & $5(39 \%)$ & 0 & \\
\hline College/university master & $1(8 \%)$ & $3(60 \%)$ & \\
\hline \multicolumn{4}{|l|}{ Civil status } \\
\hline Married/cohabitant & $10(77 \%)$ & $3(60 \%)$ & \\
\hline Single & $3(23 \%)$ & $2(40 \%)$ & \\
\hline Experience pain & $9(69 \%)$ & $3(60 \%)$ & \\
\hline
\end{tabular}

Age, height, weight, and time since injury are presented in median with maximum and minimum in parentheses; remaining variables are presented in numbers counted with percent in parentheses

$B M I$ body mass index, AIS ASIA (American Spinal Injury Associations) Impairment Scale

3. CPET outcomes are shown in Table 4. None of the participants had BR $<15 \%$.

Previous measurements of $\mathrm{VO}_{2 \max }$ at $\mathrm{SRH}$ are sourced between years 2005 and 2014. The time since previous tests was 2-11 years (median 4 years). Two of the participants had no previous test results and were therefore excluded from the analyses presented in Fig. 1. Figure 1 shows a dot plot of individual absolute $\mathrm{VO}_{2 \max }$ from the period before they started participating in the exercise group (median score $\mathrm{VO}_{2 \max } 1.171 \mathrm{~min}^{-1}$ ) and from the present measurements (median score $\mathrm{VO}_{2 \max } 1.131 \mathrm{~min}^{-1}$ ). The present measurements are reduced by $0.031 \mathrm{~min}^{-1}$ when compared with previous measures. The difference was not significant $(p>0.05)$.
There was a significant negative correlation between $\mathrm{VO}_{2 \max }\left(\mathrm{ml} \mathrm{kg}^{-1} \mathrm{~min}^{-1}\right)$ and total FM (Spearman's rho $=$ $-0.7 ; p<0.01)$. Similarly, a significant negative correlation was observed between $\mathrm{VO}_{2 \max }\left(\mathrm{ml} \mathrm{kg}^{-1} \mathrm{~min}^{-1}\right)$ and total LM (Spearman's rho $=-0.57, p<0.05$ ). No correlation was observed between absolute or relative $\mathrm{VO}_{2 \max }$ and $\mathrm{LM}$ in participants' arms.

\section{Self-reported quality of life}

Outcomes from the QOL questionnaires are presented in Fig. 2. Satisfaction with mental health was slightly higher (median 7.5) than satisfaction with personal environments and physical health (median 7). A positive correlation was seen between physical and mental health (Fig. 3).

\section{Discussion}

The main findings of the present study were that persons with SCI who exercise regularly at SRHOCE had average to excellent cardiorespiratory fitness compared to an untrained SCI population [18]. This group also reported rather high QOL. Participants with TP had significantly reduced $\mathrm{FEV}_{1}$ (\% predicted) compared with PP, but their BR revealed no ventilatory limitations. Despite variations in the groups, being slightly overweight was common for both groups.

\section{Body composition}

In agreement with Wahman et al., overweight seemed to be a common variable when adjusting for specific body mass index (BMI) cutoff values for persons with SCI (median $\mathrm{BMI}=24 \mathrm{~kg} \mathrm{~m}^{-2}$ ) [19]. A healthy BMI is proposed to be no more than $22 / 23 \mathrm{~kg} \mathrm{~m}^{-2}$ for persons with $\mathrm{SCI}$, because each BMI grade consists of greater fat mass [20]. According to Kocina et al. [21], persons with SCI and total fat mass $>25 \%$ (males) and 32\% (females) are at high risk of developing secondary diseases. As Table 2 indicates, fat percent is above these percentages in both PP and TP. As a result of changes in body composition after a SCI, VAT is expected to be greater compared to the general population. An increase of $20 \%$ in VAT volume for every unit increase of BMI has been suggested [22]. This is consistent with our findings (median VAT $=1032 \mathrm{~cm}^{3}$ ), but the range in the present study revealed a huge variation $\left(89-3379 \mathrm{~cm}^{3}\right)$.

\section{Bone mineral density}

No difference was observed in total BMD between the PP and TP group, or between motor complete and incomplete injuries. This might be explained by the overall small sample size. However, we did not measure BMD in femur 
Table 2 Differences in body composition, bone mineral density (BMD), lung function, diffusion capacity of carbon monoxide (DL $\mathrm{CO}_{\mathrm{CO}}$ ), exhaled nitric oxide $\left(\mathrm{FE}_{\mathrm{NO}}\right)$, and maximal oxygen uptake $\left(\mathrm{VO}_{2 \max }\right)$ in paraplegics AIS A-B and AIS C-D, and tetraplegics AIS A-B and AIS C

\begin{tabular}{|c|c|c|c|}
\hline Variable & Paraplegia AIS A-B $(n=9)$ & Paraplegia AIS C-D $(n=4)$ & $p$ value \\
\hline $\mathrm{BMD}\left(\mathrm{g} \mathrm{cm}^{-2}\right)$ & $0.942(0.885-1.312)$ & $1.087(1.059-1.203)$ & 0.217 \\
\hline $\operatorname{VAT}\left(\mathrm{cm}^{3}\right)$ & $971(584-2619)$ & $1385(296-3054)$ & 0.440 \\
\hline FM (kg) & $28.02(13.53-31.81)$ & $36.09(20.03-50.99)$ & 0.090 \\
\hline FM (\% of total body mass) & $40(25-51)$ & $44(35-51)$ & 0.395 \\
\hline $\mathrm{LM}(\mathrm{kg})$ & $36.41(27.73-51.84)$ & $41.33(37.79-59.28)$ & 0.217 \\
\hline LM (\% of total body mass) & $58(48-72)$ & $55(48-63)$ & 0.537 \\
\hline LM arms (g) & $5518(3752-8539)$ & $4555(4175-8618)$ & 0.440 \\
\hline FVC (\% predicted $)$ & $92.8(59.6-121.3)$ & $123.9(91.0-130.9)$ & 0.045 \\
\hline $\mathrm{FEV}_{1}(\%$ predicted $)$ & $88.2(61.1-119.0)$ & $109.8(91.0-119.1)$ & 0.045 \\
\hline MVV (\% predicted) & $87.4(60.1-133.5)$ & $111.9(100.0-124.9)$ & 0.165 \\
\hline $\mathrm{DL}_{\mathrm{CO}}(\%)$ & $72.3(55.8-103.5)$ & $91.9(89.1-97.7)$ & 0.123 \\
\hline $\mathrm{FE}_{\mathrm{NO}}(\mathrm{ppb})$ & $20.9(6.7-42.2)$ & $24.5(16.1-37.6)$ & 0.497 \\
\hline $\mathrm{VO}_{2 \max }\left(\mathrm{ml} \mathrm{min}{ }^{-1}\right)$ & $1053(914-1441)$ & $1270(1066-1663)$ & 0.165 \\
\hline $\mathrm{VO}_{2 \max }\left(\mathrm{ml} \mathrm{kg}^{-1} \min ^{-1}\right)$ & $17.06(12.15-25.28)$ & $14.43(14.13-22.63)$ & 0.355 \\
\hline Variable & Tetraplegia AIS A-B $(n=3)$ & Tetraplegia AIS C $(n=2)$ & $p$ value \\
\hline $\operatorname{BMD}\left(\mathrm{g} \mathrm{cm}^{-2}\right)$ & $1.106(1.034-1.299)$ & $1.117(1.095-1.138)$ & 1.000 \\
\hline $\operatorname{VAT}\left(\mathrm{cm}^{3}\right)$ & $2570(1401-3379)$ & $442(89-795)$ & 0.083 \\
\hline FM (kg) & $34.38(23.52-38.78)$ & $17.48(8.88-26.07)$ & 0.236 \\
\hline FM (\% of total body mass) & $46(32-47)$ & $32(26-38)$ & 0.248 \\
\hline $\mathrm{LM}(\mathrm{kg})$ & $44.11(39.74-49.26)$ & $34.11(25.69-42.53)$ & 0.248 \\
\hline LM (\% of total body mass) & $52(52-65)$ & $65(60-10)$ & 0.236 \\
\hline LM arms (g) & $6506(4726-7117)$ & $3356(3055-3657)$ & 0.083 \\
\hline FVC (\% predicted) & $83.9(66.1-91.3)$ & $61.7(46.0-77.3)$ & 0.248 \\
\hline $\mathrm{FEV}_{1}(\%$ predicted $)$ & $81.6(68.6-83.2)$ & $62.3(43.0-81.5)$ & 0.248 \\
\hline MVV (\% predicted) & $86.2(82.6-90.8)$ & $83.1(57.0-109.2)$ & 1.000 \\
\hline $\mathrm{DL}_{\mathrm{CO}}(\%)$ & $67.2(66.1-75.93)$ & $69.9(56.0-83.9)$ & 1.000 \\
\hline $\mathrm{FE}_{\mathrm{NO}}(\mathrm{ppb})$ & $22.0(19.4-29.2)$ & $54.4(49.2-59.6)$ & 0.083 \\
\hline $\mathrm{VO}_{2 \max }\left(\mathrm{ml} \mathrm{min}{ }^{-1}\right)$ & $1078(845-1331)$ & $1062(771-1354)$ & 1.000 \\
\hline $\mathrm{VO}_{2 \max }\left(\mathrm{ml} \mathrm{kg}^{-1} \min ^{-1}\right)$ & $14.29(9.91-17.33)$ & $20.06(19.1-21.01)$ & 0.083 \\
\hline
\end{tabular}

Results are presented as median with minimum and maximum in parentheses

$V A T$ visceral fat tissue, $F M$ fat mass, $L M$ lean mass, $F V C$ forced vital capacity, $F E V_{l}$ forced expiratory volume in $1 \mathrm{~s}, M V V$ maximal voluntary ventilation, $p p b$ parts per billion, $n s$ not significant,

$p \leq 0.05=$ significant different

specifically and thus we cannot exclude osteoporosis in any of the groups. Our results of total body BMD are therefore of limited utility. Total BMD does not indicate a risk of osteoporosis in the femur, which is the limb at highest risk of developing osteoporosis in persons with SCI [23]. Total BMD revealed a risk of osteoporosis in three of the participants (BMD Z-score $\leq-2.0$ ).

\section{Pulmonary function}

We found significant differences in $\mathrm{FEV}_{1}$ (\% predicted) due to injury level. In agreement with Linn et al. [24], reduction in pulmonary function was seen in persons with TP. MVV was within normal range in both groups [14], and $\mathrm{DL}_{\mathrm{CO}}(\%$ predicted) was slightly reduced in both groups. Because of the small sample size and unequal distribution of participants with TP $(n=5)$ versus PP $(n=13)$, we could not expect to detect significant differences. Although only $\mathrm{FEV}_{1}$ (\% predicted) revealed significant difference between PP and TP, FVC (\% predicted) showed borderline significant differences $(p=0.056)$. We can assume that with a greater number of participants in both groups, we might be able to detect a significant difference. Nonetheless, our findings indicate that pulmonary function is affected by higher SCI, indicating our results are within normal range for SCI and injury level. However, ventilation seemed not to be a limiting factor for cardiorespiratory fitness in the present study. In the general population, BR is normally between $20 \%$ and $40 \%$, and values $<15 \%$ may indicate ventilatory restrictions [25]. In the present study, BR varied from $16 \%$ to $64 \%$, 
Table 3 Individual results of body composition and bone mineral density (BMD), pulmonary function, ventilatory capacity, and diffusion capacity of carbon monoxide $\left(\mathrm{DL}_{\mathrm{CO}}\right)(n=18)$

\begin{tabular}{|c|c|c|c|c|c|c|c|c|c|c|c|c|c|}
\hline Sex & LL & AISA & LM (kg) & LM (\%) & $\mathrm{FM}(\%)$ & $\operatorname{VAT}\left(\mathrm{cm}^{3}\right)$ & $\begin{array}{l}\mathrm{BMD} \\
\left(\mathrm{g} \mathrm{cm}^{2}\right)\end{array}$ & $\begin{array}{l}\text { BMD } \\
Z \text {-score }\end{array}$ & $\mathrm{FVC}(\%)$ & $\mathrm{FEV}_{1}(\%)$ & $\begin{array}{l}\text { MVV } \\
\left(1 \mathrm{~min}^{-1}\right)\end{array}$ & MVV (\%) & $\mathrm{DL}_{\mathrm{CO}}(\%)$ \\
\hline M & PP & A & 43.4 & 66 & 31 & 849 & 1.176 & 0.4 & 100.3 & 88.2 & 126.7 & 93.3 & 68.5 \\
\hline M & PP & A & 35.7 & 63 & 35 & 980 & 0.943 & -1.6 & 59.6 & 61.1 & 82.5 & 66.9 & 99.8 \\
\hline M & $\mathrm{TP}$ & $\mathrm{C}$ & 42.5 & 60 & 38 & 795 & 1.095 & -0.9 & 77.3 & 81.5 & 153.9 & 109.2 & 83.7 \\
\hline $\mathrm{M}$ & $\mathrm{PP}$ & $\mathrm{D}$ & 59.3 & 52 & 46 & 3054 & 1.203 & -0.4 & 91.0 & 91.0 & 104.8 & 100.0 & 93.0 \\
\hline M & $\mathrm{PP}$ & A & 41.1 & 72 & 25 & 721 & 0.935 & -1.5 & 73.1 & 76.7 & 107.7 & 85.1 & 55.8 \\
\hline M & PP & A & 51.8 & 63 & 35 & 2619 & 0.885 & -3.1 & 94.5 & 92.1 & 134.7 & 103.1 & 72.3 \\
\hline M & $\mathrm{TP}$ & B & 49.3 & 65 & 32 & 1401 & 1.299 & 0.7 & 91.3 & 83.2 & 112.1 & 82.6 & 67.2 \\
\hline M & $\mathrm{TP}^{\mathrm{a}}$ & A & 39.7 & 52 & 46 & 2570 & 1.034 & 0.1 & 83.9 & 81.6 & 113.2 & 90.8 & 75.9 \\
\hline M & $\mathrm{TP}$ & A & 44.1 & 52 & 47 & 3379 & 1.106 & -1.3 & 66.1 & 68.6 & 86.2 & 66.8 & 66.1 \\
\hline $\mathrm{F}$ & PP & A & 30.4 & 48 & 51 & 971 & 0.925 & -0.9 & 73.9 & 88.2 & 58.0 & 60.1 & 59.9 \\
\hline $\mathrm{F}$ & $\mathrm{TP}$ & $\mathrm{C}$ & 25.7 & 70 & 26 & 89 & 1.138 & 2.0 & 46.0 & 43.0 & 56.5 & 57.0 & 56.0 \\
\hline $\mathrm{F}$ & PP & A & 36.4 & 53 & 45 & 868 & 1.093 & 0.4 & 92.8 & 89.2 & 85.6 & 87.4 & 76.5 \\
\hline $\mathrm{F}$ & PP & A & 41.8 & 56 & 43 & 1268 & 0.887 & -1.7 & 88.1 & 86.3 & 84.9 & 84.5 & 68.6 \\
\hline $\mathrm{F}$ & PP & A & 34.3 & 52 & 46 & 1090 & 1.312 & 2.8 & 107.0 & 96.7 & 133.0 & 133.5 & 78.3 \\
\hline $\mathrm{F}$ & PP & $\mathrm{D}$ & 37.8 & 63 & 35 & 296 & 1.059 & 0.9 & 130.9 & 118.3 & 112.9 & 120.3 & 97.7 \\
\hline $\mathrm{F}$ & PP & $\mathrm{C}$ & 40.0 & 48 & 51 & 1687 & 1.090 & 0.3 & 126.2 & 119.1 & 111.1 & 124.9 & 90.8 \\
\hline $\mathrm{F}$ & PP & $\mathrm{D}$ & 42.6 & 57 & 42 & 1083 & 1.085 & 0.9 & 121.5 & 101.2 & 89.3 & 103.5 & 89.1 \\
\hline $\mathrm{F}$ & PP & A & 27.7 & 58 & 41 & 584 & 0.942 & -0.1 & 121.3 & 119.0 & 117.0 & 133.3 & 103.4 \\
\hline
\end{tabular}

$M$ male, $F$ female, $L L$ level of lesion, $P P$ paraplegia, $T P$ tetraplegia, $L M$ lean mass, $L M \% \%$ of total body fat, $F M \% \%$ fat of total body mass, $V A T$ visceral adipose tissue, $B M D$ bone mineral density, $F V C$ forced vital capacity, $F V C \% \%$ of predicted values, $F E V_{1}$ forced expiratory volume in $1 \mathrm{~s}$, $F E V_{1} \% \%$ of predicted values, $M V V$ maximal voluntary ventilation, $M V V \% \%$ of predicted values, $D L_{C O}$ diffusion capacity of carbon monoxide, $D L_{C O} \% \%$ of predicted values

a Participant is originally a PP at level T1, but is considered as a TP in this study

suggesting that pulmonary function did not restrict maximal exercise performance. This is presumably due to the involvement of small muscle groups with less oxygen demand when compared to a whole body workout.

\section{Cardiorespiratory fitness}

We did not detect significant differences in $\mathrm{VO}_{2 \max }$ between PP and TT, or between motor compete and incomplete, which would have been expected based on previous research [18]. Simmons et al. [18] developed normative values with reference ranges for untrained males and females with SCI. Cardiorespiratory fitness values were grouped into reference categories of percentile ranking (i.e., poor $<20 \%$; fair $20-40 \%$; average $40-60 \%$; good $60-80 \%$; excellent $80-100 \%$ ) according to Janssen et al. [26]. Because of a small number of females $(n=26)$, Simmons et al. [18] did not define specific categories for females, other than provide female median values separately. In the present study, we could not show significant differences in $\mathrm{VO}_{2 \max }$ between the sexes, and the median from both sexes as a single group was used to categorize persons with TP and PP. The present study participants were significantly older (median age $=58$ years in PP, 47 years in TP) than participants from the Simmons et al. study (mean age $=36$ years in PP, 35 years in TP); thus, all of these categories will probably underestimate cardiorespiratory fitness in our sample. $\mathrm{VO}_{2 \max }$ is expected to decrease by about $10 \%$ every decade when a person is $>30$ years, and females tend to have $10 \%$ lower values than males [27]. When adjusting for age, categories for PP and TP in our sample were as follows: PP: $\mathrm{VO}_{2 \max }\left(\mathrm{ml} \mathrm{kg}^{-1} \min ^{-1}\right)=$ good, PP: $\mathrm{VO}_{2 \max }(\mathrm{ml}$ $\left.\min ^{-1}\right)=$ good, TP: $\mathrm{VO}_{2 \max }\left(\mathrm{ml} \mathrm{kg}^{-1} \min ^{-1}\right)=$ excellent, TP: $\mathrm{VO}_{2 \max }\left(\mathrm{ml} \mathrm{min}^{-1}\right)=$ excellent. Thus, cardiorespiratory fitness in our sample can be described as good to excellent compared to an untrained SCI population.

A retrospective glance (Fig. 1) indicated that the cardiorespiratory fitness median was not significantly reduced compared with previous results. As we had no overview of any dietary changes during these years, we chose to compare the absolute $\mathrm{VO}_{2 \max }$ value $\left(\mathrm{ml} \mathrm{min}^{-1}\right)$. Still, eventually dietary changes may have affected the results. A medical records search provided retrospective test results between 2005 and 2014. With a median of four years since the previous test, we expected a greater decrease in $\mathrm{VO}_{2 \max }$. More precisely, according to the median we expected a $4 \%$ reduction, and $\mathrm{VO}_{2 \max }$ should have been reduced by 0.051 $\min ^{-1}$ [27]. This is $0.021 \mathrm{~min}^{-1}$ more than what our 
Table 4 Individual results and outcomes of cardiopulmonary exercise test $(n=18)$

\begin{tabular}{|c|c|c|c|c|c|c|c|c|c|}
\hline Sex & LL & AISA & $\mathrm{VO}_{2 \max } \mathrm{ml} \mathrm{min}^{-1}$ & $\mathrm{VO}_{2 \max } \mathrm{ml} \mathrm{kg}^{-1} \min ^{-1}$ & $\mathrm{RER}_{\max }$ & $\mathrm{VE}_{\max }$ & $\mathrm{HR}_{\max }$ & Borg $_{\max }$ & $\mathrm{BR}(\%)$ \\
\hline M & $\mathrm{PP}$ & A & 1328 & 20.1 & 1.36 & 84 & 143 & 17 & 34 \\
\hline M & $\mathrm{PP}$ & A & 1441 & 25.3 & 1.17 & 51 & 164 & & 38 \\
\hline M & $\mathrm{TP}$ & $\mathrm{C}$ & 1354 & 19.1 & 1.22 & 72 & 163 & 18 & 53 \\
\hline $\mathrm{M}$ & $\mathrm{PP}$ & $\mathrm{D}$ & 1039 & 16.3 & 1.41 & 44 & 150 & & 24 \\
\hline M & PP & A & 1663 & 14.7 & 1.25 & 88 & 132 & & 16 \\
\hline M & $\mathrm{PP}$ & A & 969 & 17.1 & 1.14 & 60 & 139 & 17 & 44 \\
\hline M & $\mathrm{TP}$ & B & 1249 & 15.2 & 1.26 & 79 & 135 & 17 & 41 \\
\hline M & $\mathrm{TP}^{\mathrm{a}}$ & A & 1078 & 14.3 & 1.51 & 40 & 113 & & 64 \\
\hline M & $\mathrm{TP}$ & A & 1331 & 17.3 & 1.15 & 72 & 106 & 19 & 36 \\
\hline $\mathrm{F}$ & $\mathrm{PP}$ & A & 845 & 9.9 & 1.02 & 41 & 106 & 18 & 52 \\
\hline $\mathrm{F}$ & $\mathrm{TP}$ & $\mathrm{C}$ & 771 & 21.0 & 1.07 & 26 & 152 & & 54 \\
\hline $\mathrm{F}$ & $\mathrm{PP}$ & A & 991 & 14.5 & 1.41 & 51 & 166 & 19 & 40 \\
\hline $\mathrm{F}$ & $\mathrm{PP}$ & A & 914 & 12.2 & 1.09 & 38 & 147 & 19 & 55 \\
\hline $\mathrm{F}$ & $\mathrm{PP}$ & A & 1346 & 20.4 & 1.32 & 93 & 147 & 19 & 30 \\
\hline $\mathrm{F}$ & PP & $\mathrm{D}$ & 1353 & 22.6 & 1.29 & 82 & 169 & 17 & 27 \\
\hline $\mathrm{F}$ & PP & $\mathrm{C}$ & 1187 & 14.1 & 1.25 & 61 & 162 & 19 & 45 \\
\hline $\mathrm{F}$ & PP & $\mathrm{D}$ & 1066 & 14.2 & 1.23 & 60 & 126 & 18 & 33 \\
\hline $\mathrm{F}$ & PP & A & 1053 & 22.6 & 1.23 & 58 & 171 & & 50 \\
\hline
\end{tabular}

$M$ male, $F$ female, $L L$ level of lesion, $P P$ paraplegia, $T P$ tetraplegia, $V O_{2 \max }$ maximal oxygen uptake, $R E R_{\max }$ maximal respiratory exchange ratio,

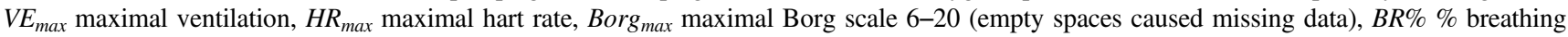
reserve

${ }^{a}$ Participant is originally a PP at level T1, but is considered as a TP in this study

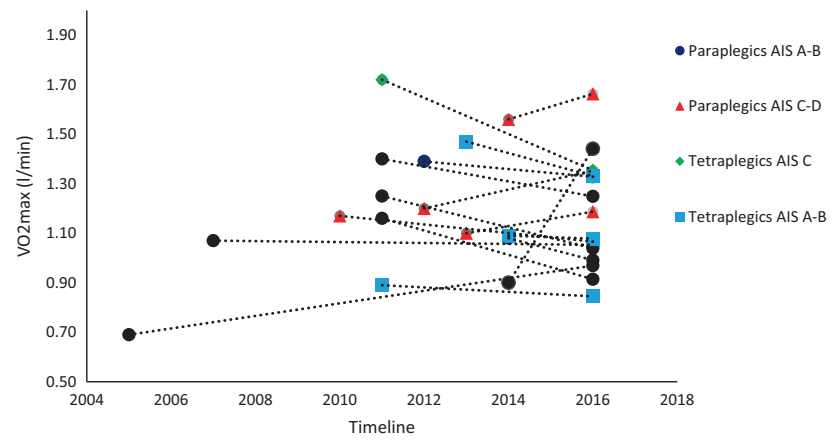

Fig. 1 Dot plot of $\mathrm{VO}_{2 \max }\left(1 \mathrm{~min}^{-1}\right)$ from previous results and results from the present study in 2016. Time since previous test varied from 2 to 11 years. Each dot represents individual results from previous and recent $\mathrm{VO}_{2 \max }\left(1 \mathrm{~min}^{-1}\right)$. The dotted line binds together previous and present results and indicates a positive or negative direction $(n=16)$

analyses revealed. Even though the median tended to be lower, the dot plot (Fig. 1) indicates that some of the participants had improvements in their $\mathrm{VO}_{2 \max }\left(1 \mathrm{~min}^{-1}\right)$. Our descriptive data show that $81 \%$ of the participants were more physically active after the exercise group was created in April 2015. It is tempting to assume that the absence of a significant reduction in $\mathrm{VO}_{2 \max }$ is associated with regular exercise. Still, such a comparison entails several methodological weaknesses and should be interpreted with caution.

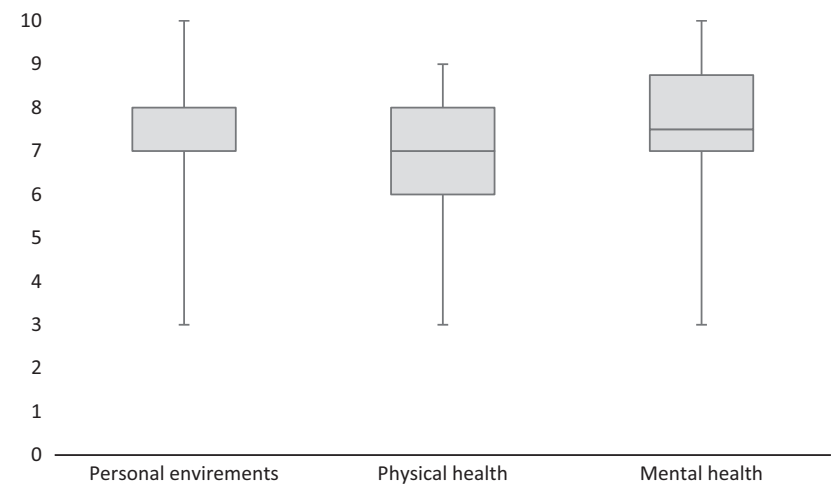

Fig. 2 Self-reported satisfaction for personal circumstances, physical and mental health. The line in the middle of the box corresponds to the median, while the top and bottom of the boxes are the 25th and 75th percentiles. The whiskers show minimum and maximum range. Box plot for personal environments reveals that the 25 th percentile is the same as the median

\section{Self-reported quality of life}

It has been reported that persons with SCI have lower life satisfaction than the general population [28]. In our study, QOL was ranked as rather satisfying (Fig. 2). This is slightly higher than Norwegian SCI results from 2016 [29]. Results from NorSCIR were collected from persons with newly acquired SCI that occurred during their hospital stay. 


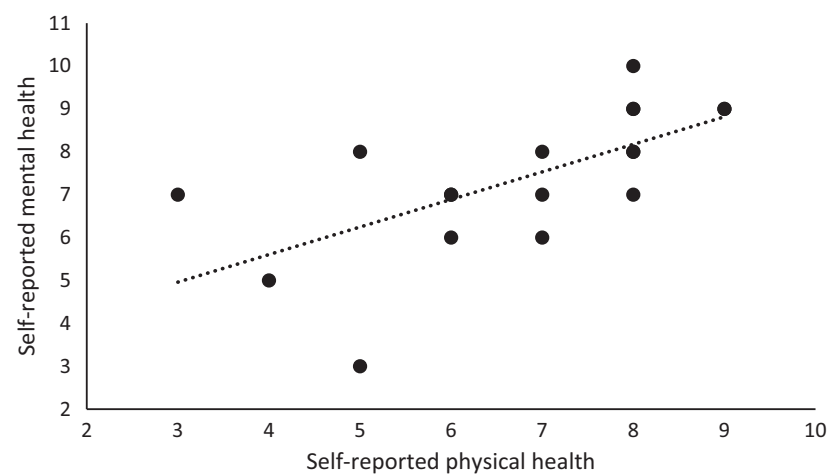

Fig. 3 Correlation of self-reported physical and mental health. The correlation is significant positive (Spearman's rho $=0.739, p<0.05$ )

Since QOL has been reported to increase in accordance with time since injury, these findings were in consistence with previous research [30]. Although there have been different findings due to QOL and long-standing SCI, the relationship between QOL and physical activity appears to be valid $[2,28,31]$. Our findings support this relationship. We also found that self-reported satisfaction with physical health strongly correlated with mental health (Fig. 3). However, it has been reported that exercise capacity is related to higher life satisfaction [32]. No association between $\mathrm{VO}_{2 \max }$ and QOL was found in the present study $(p>0.05)$. The absence of significance may be explained by the small sample size or the complexity of what defines one's QOL. It will be interesting to explore the impact of the social environment and support from peers in a group setting on the state of participants QOL in future studies.

\section{Methodical discussion}

What strengthens the methods was that all of the tests, except for the DXA scan, were conducted by the same staff. The staff received the same training and followed the same protocol for each test. All clinical measurements were performed according to the gold standard test methods, were previously validated, and were considered to give robust, objective data. Evaluation of the CPET was done with guidance from staff at the clinical physiological laboratory at SRH. Considering end criteria and expected HR based on age and level of injury, there was reason to assume that the participants roughly achieved a maximal loaded test.

There were also study limitations. First, our crosssectional study design made us unable to explore the causality of regular exercise and health. There is a great possibility that our associations were predicted by uncontrolled confounding factors. As for the small sample size and variations considering age and level and completeness of injuries, our findings may not be adequate to make generalizations about the SCI population. The small number of persons with TP also made it difficult to compare outcomes between persons with PP. However, the SCI population is scarce, and the sample of 18 males and females may provide useful information. We hope that our descriptive results can act as a basis for comparison in future research.

DXA measurements gave us concrete information about body composition. What may have challenged the reliability was that the measurements were performed at two different places by different staff. Some participants were not informed that their bladder should have been emptied, which may have influenced the results due to body water concentration. Metal was not corrected for and may have influenced total BMD. An important limitation in this study is that only total body BMD was measured. Total BMD does not correlate with potential osteoporosis in the distal femur, which has previously been reported to be the most sensitive bone site for assessing bone loss by DXA [22] Thus, for future studies, we recommend specific assessments of the distal femur. Hemoglobin levels were automatically inserted in $\mathrm{DL}_{\mathrm{CO}}$ assessments and probably do not concur with individual values and may have been a source of error. Confounding factors such as different settings and test leaders limit our comparison of absolute $\mathrm{VO}_{2 \max }$ with previous results. Finally, data sourced from the questionnaires involve weaknesses regarding validity and reliability. The international SCI QOL data set has not yet been validated, and some of the articles that were discussed used different questionnaires in the QOL survey.

Even though the classes at SRHOCE were established with a purpose of fulfilling a minimum of the physical activity guidelines, intensity was reserved for individual efforts. As Jörgensen et al. presented regarding exercise intensity [4], we do not know if participants in the present study achieved moderate to vigorous intensity due to the class structure or individual efforts. To get an indication, we could have used an HR monitor or other activity monitoring devices to obtain better control with regard to intensity. Our inclusion criteria are rather vague in the sense that some participants exercised more than what was considered to be the minimum of two times a week. This limits our ability to discuss whether fulfilling minimum guidelines was associated with our findings of health status.

\section{Considerations of health status and requests for future research}

Our research contains limitations that limits its generalizability and ability to draw conclusions. We will cautiously state that we have surveyed health status, knowing that health is a very complex phenomenon. However, standardized methods have provided outcomes that can be used for comparison in future research. Hence, we encourage 
researchers to establish new interventions or controls to see if our assumptions are reasonable. A newly published article by Nightingale et al. calls for an increase in the SCI guidelines exercise intensity for physical activity [9]. For now, our findings support positive health associations with participation in physical exercise as presented by Pelletier et al. [6]. On this basis, we will continue to recommend that institutions and persons with SCI promote and develop exercise classes as established by the Canadian guidelines.

In conclusion, persons with SCI who exercise regularly at least twice a week responded with positive associations for health outcomes. Persons with PP and TP were slightly overweight, cardiorespiratory fitness indicated good to excellent aerobic capacity, and QOL was ranked as rather satisfying. Future research is needed to validate or strengthen our findings.

Acknowledgements The study was supported by The Norwegian School of Sport Science and Sunnaas Rehabilitation Hospital. A big thank to Dinasty Pramadita for untimely help during testing at the lab, and test colleagues at Sunnaas Rehabilitation Hospital.

\section{Compliance with ethical standards}

Conflict of interest The authors declare that they have no competing interests.

Ethical approval The Regional Medical Ethical Committee (REK), Eastern Norway (REK number 2016/1110), approved the study. We certify that the study was performed in accordance with the Declaration of Helsinki and followed all applicable institutional and governmental regulations concerning the ethical use of human volunteers during the study course.

Open Access This article is licensed under a Creative Commons Attribution 4.0 International License, which permits use, sharing, adaptation, distribution and reproduction in any medium or format, as long as you give appropriate credit to the original author(s) and the source, provide a link to the Creative Commons license, and indicate if changes were made. The images or other third party material in this article are included in the article's Creative Commons license, unless indicated otherwise in a credit line to the material. If material is not included in the article's Creative Commons license and your intended use is not permitted by statutory regulation or exceeds the permitted use, you will need to obtain permission directly from the copyright holder. To view a copy of this license, visit http://creativecommons. org/licenses/by/4.0/

\section{References}

1. Garshick E, Kelley A, Cohen SA, Garrison A, Tun CG, Gagnon $\mathrm{D}$, et al. A prospective assessment of mortality in chronic spinal cord injury. Spinal Cord 2005;43:408-16.

2. Ditor DS, Latimer AE, Ginis KAM, Arbour KP, Mccartney N, Hicks AL. Maintenance of exercise participation in individuals with spinal cord injury: effects on quality of life, stress and pain. Spinal Cord 2003;41:446.

3. Hicks AL, Martin Ginis KA, Pelletier CA, Ditor DS, Foulon B, et al. The effects of exercise training on physical capacity, strength, body composition and functional performance among adults with spinal cord injury: a systematic review. Spinal Cord 2011;49:1103-27.

4. Jörgensen S, Martin Ginis KA, Lexell J, Leisure time physical activity among older with long-term spinal cord injury. Spinal Cord. 2017;55:848-856.

5. Ginis KA, Hicks AL, Latimer AE, Warburton DE, Bourne C, Ditor DS, et al. The development of evidence-informed physical activity guidelines for adults with spinal cord injury. Spinal Cord 2011;49:1088-96.

6. Pelletier CA, Totosy de Zepetnek JO, MacDonald MJ, Hicks AL. A 16-week randomized controlled trial evaluating the physical activity guidelines for adults with spinal cord injury. Spinal Cord 2015;53:363-7.

7. Totosy de Zepetnek JO, Pelletier CA, Hicks AL, MacDonald MJ. Following the physical activity guidelines for adults with spinal cord injury for 16 weeks does not improve vascular health: a randomized controlled trial. Arch Phys Med Rehabil 2015;96:1566-75.

8. Tweedy SM, Beckman EM, Geraghty TJ, Theisen D, Perret C, Harvey LA, et al. Exercise and sports science Australia (ESSA) position statement on exercise and spinal cord injury. Sci Med Sport. 2017;20:108-115.

9. Nightingale TE, Metcalfe RS, Vollaard NB, Bilzon JL, Exercise guidelines to promote cardiometabolic health in spinal cord injured humans: time to raise the intensity?. Arch Phys Med Rehabil. 2017;98:1693-1704.

10. Nery MB, Driver S, Vanderbom KA. Systematic framework to classify the status of research on spinal cord injury and physical activity. Arch Phys Med Rehabil 2013;94:2027-31.

11. Baim S, Binkley N, Bilezikian JP, Kendler DL, Hans DB, Lewiecki EM, et al. Official positions of the International Society for Clinical Densitometry and executive summary of the 2007 ISCD Position Development Conference. J Clin Densitom 2008;11:75-91.

12. Miller MR, Hankinson J, Brusasco V, Burgos F, Casaburi R, Coates A, et al. Standardisation of spirometry. Eur Respir J 2005;26:319-38.

13. Macintyre N, Crapo RO, Viegi G, Johnson DC, van der Grinten $\mathrm{CP}$, Brusasco V, et al. Standardisation of the single-breath determination of carbon monoxide uptake in the lung.Eur Respir $\mathbf{J}$ 2005;26:720-35.

14. Quanjer PH, Tammeling GJ, Cotes JE, Pedersen OF, Peslin R, Yernault JC. Lung volumes and forced ventilatory flows. Report Working Party Standardization Of Lung Function Tests, European Community for Steel and Coal. Official Statement of the European Respiratory Society. Eur Respir J Suppl 1993;16:5-40.

15. ATS. ATS/ERS recommendations for standardized procedures for the online and offline measurement of exhaled lower respiratory nitric oxide and nasal nitric oxide, 2005. Am J Respir Crit Care Med 2005;171:912-30.

16. Nes BM, Janszky I, Wisloff U, Stoylen A, Karlsen T. Agepredicted maximal heart rate in healthy subjects: the HUNT fitness study. Scand J Med Sci Sports 2013;23:697-704.

17. Charlifue S, Post MW, Biering-Sorensen F, Catz A, Dijkers M, Geyh S, et al. International Spinal Cord Injury Quality Of Life Basic Data Set. Spinal Cord2012;50:672-5.

18. Simmons OL, Kressler J, Nash MS. Reference fitness values in the untrained spinal cord injury population. Arch Phys Med Rehabil 2014;95:2272-8.

19. Wahman K, Nash MS, Lewis JE, Seiger Å, Levi R, Cardiovascular disease risk and the need for prevention after paraplegia determined by conventional multifactorial risk models: the Stockholm spinal cord injury study. J Rehabil Med. 2011;43:237-42. 
20. Jones LM, Legge M, Goulding A. Healthy body mass index values often underestimate body fat in men with spinal cord injury. Arch Phys Med Rehabil 2003;84:1068-71.

21. Kocina P. Body composition of spinal cord injured adults. Sports Med 1997;23:48-60.

22. Cirnigliaro CM, LaFountaine MF, Dengel DR, Bosch TA, Emmons RR, Kirshblum SC, et al. Visceral adiposity in persons with chronic spinal cord injury determined by dual energy X-ray absorptiometry. Obesity 2015;23:1811-7.

23. Gaspar AP, Lazaretti-Castro M, Brandao CM. Bone mineral density in spinal cord injury: an evaluation of the distal femur. J Osteoporos 2012;2012:519754.

24. Linn WS, Spungen AM, Gong H Jr, Adkins RH, Bauman WA, Waters RL. Forced vital capacity in two large outpatient populations with chronic spinal cord injury. Spinal Cord 2001;39:263-8.

25. Wasserman K. Principles of exercise testing and interpretation: including pathophysiology and clinical applications. 5th ed. Philadelphia: Wolters Kluwer Health/Lippincott Williams and Wilkins; 2013..

26. Janssen TW, Dallmeijer AJ, Veeger DJ, van der Woude LH. Normative values and determinants of physical capacity in individuals with spinal cord injury. $J$ Rehabil Res Dev 2002;39:29-39.

27. Edvardsen E, Hem E, Anderssen SA, Reddy H, End criteria for reaching maximal oxygen uptake must be strict and adjusted to sex and age: a cross-sectional study. PLoS ONE. 2014;9:e85276

28. Lidal IB, Veenstra M, Hjeltnes N, Biering-Sorensen F. Healthrelated quality of life in persons with long-standing spinal cord injury. Spinal Cord 2008;46:710-5.

29. Stensland E. Norsk ryggmargsskaderegister St. Olavs Hospital HF2016. https://www.kvalitetsregistre.no/registers/561/resultater.

30. Adriaansen JJ, Ruijs LE, van Koppenhagen CF, van Asbeck FW, Snoek GJ, van Kuppevelt D, et al. Secondary health conditions and quality of life in persons living with spinal cord injury for at least ten years. J Rehabil Med 2016;48:853-60.

31. Lannem AM, Sorensen M, Froslie KF, Hjeltnes N. Incomplete spinal cord injury, exercise and life satisfaction. Spinal Cord 2009;47:295-300.

32. van Koppenhagen $\mathrm{CF}$, Post $\mathrm{M}$, de Groot $\mathrm{S}$, van Leeuwen $\mathrm{C}$, van Asbeck F, Stolwijk-Swuste J, et al. Longitudinal relationship between wheelchair exercise capacity and life satisfaction in patients with spinal cord injury: a cohort study in the Netherlands. J Spinal Cord Med 2014;37:328-37. 